\title{
Hot topic: Microstructure quantification by scanning electron microscopy and image analysis of goat cheese curd
}

\author{
S. Rovira, ${ }^{1}$ M. B. López, E. Ferrandini, and J. Laencina \\ Department of Food Technology, Human Nutrition and Bromatology, Veterinary Faculty, University of Murcia, Espinardo, E-30071, Murcia, Spain
}

\begin{abstract}
Five microstructural parameters of goat cheese curd (number of pores, their area and perimeter, strand thickness, and porosity) were studied by scanning electron microscopy and image analysis. Image analysis was used to characterize and quantify differences in all parameters and to provide a procedure for the measurement of strand thickness. The micrographs provided visual evidence of differences in the protein matrix and were quantified by image analysis at 3 production times: 34 \pm 1 min (cutting), $154 \pm 6$ min (before molding), and $293 \pm 35$ min (after pressing). The data showed that this procedure is an adequate tool for quantifying differences in the parameters analyzed in industrial samples despite their natural heterogeneity. The procedure was reproducible and repetitive for the first 2 production times because no significant intragroup differences were observed. Significant differences were found when comparing the values of the microstructure parameters analyzed at $34 \pm 1 \mathrm{~min}$ and those corresponding to 154 \pm 6 min and $293 \pm 35$ min, but no significant differences between samples analyzed at $154 \pm 6 \mathrm{~min}$ and 293 \pm 35 min were found. All microstructure parameters analyzed were related at a significance level of at least $95 \%$. This procedure enables the characterization of the microstructure of industrial goat cheese curd.
\end{abstract}

Key words: curd microstructure, scanning electron microscopy, image analysis, quantification

\section{INTRODUCTION}

If cheese quality is to be guaranteed, technological and safety aspects cannot be ignored; thus, it is important to control all steps of the manufacturing process. The prediction of possible irregularities during the cheese manufacturing process will minimize costs as well as lessen the risk of offering consumers low-quality products. The structural organization of a cheese is an important factor for its sensory properties and also con-

Received November 10, 2010.

Accepted December 21, 2010.

${ }^{1}$ Corresponding author: silvia.rovira@um.es tributes to final product quality (Stanley, 1987). Food structure and the distribution of components influence many of the structural properties perceived by consumers, such as texture, fragility, and elasticity (Langton et al., 1996).

Cheese structure has been studied at the molecular, macroscopic, and microscopic levels by several methods. Many of the studies in this area have focused on the observation of protein clusters and how they link together to make up the cheese protein matrix. Transmission electron microscopy has shown that the size of protein aggregates is correlated to cheese stress and fragility, meaning that the stress at fracture, the modulus, and work at fracture of the cheese product can be predicted by observing the size of the protein clusters (Wium et al., 2003). Rennet coagulation, acidification, drainage, ripening, and storage have all been extensively studied. The use of scanning electron microscopy, confocal scanning laser microscopy, and transmission electron microscopy has allowed observation of changes and differences in the structure in each of the 5 parameters mentioned above. The effects of different factors, such as starter concentration, $\mathrm{pH}$, salt content, temperature, rennet type, and concentration, on the microstructure and rheological properties have also been studied (Langton et al., 1996; Thorvaldsson et al., 1999; Pinho et al., 2004).

Studies at the microscopic level using electron microscopy techniques have described cheese microstructure and pore diameters during ripening in an orientative way based on the measurement of the horizontal diameter of pores without taking into account its irregularities. However, such techniques do not allow a quantitative determination of microstructure parameters that would enable the characteristics of the cheese structure and its irregularities to be described. Ding and Gunasekaran (1998) developed a 2-dimensional to 3-dimensional image reconstruction procedure for the study of Cheddar cheese microstructure by confocal scanning laser microscopy, quantifying with good precision the variation in particle size and shape between the 2-dimensional and the reconstructed 3-dimensional images. Later, Everett and Auty (2008) pointed to the need to use 3 -dimensional images to describe the complex protein 
matrix structure in a more real and complete way because 2-dimensional images provide information only on the particle shape and surface in the first plane, without showing how the particles link together or their distribution along the $\mathrm{x}-, \mathrm{y}-$, and z-axes.

In recent years, image analysis techniques have increased and improved. Most uses of image software in this area have focused on identifying components and on measuring their diameters, shapes and distribution. Binary images from scanning electron microscopy have been used previously for a variety of measurements and quantifications. For example, Ding and Gunasekaran (1998) used image analysis to guarantee the validity of the 3-dimensional reconstruction algorithm by processing several layered digital images.

Moreover, Impoco et al. (2006) developed an ad hoc method to analyze scanning electron microscopy cheese imagery, and Dávila and Parés (2007) used image analysis to calculate the fractal dimension of the structure of heat-induced gels of plasma at different $\mathrm{pH}$ values. The different mechanical processes involved in the manufacture of cheese are expected to produce differences in the protein matrix aggregates and free cavities that define product microstructure. For this reason is important to ascertain whether different production times lead to differences in microstructure parameters.

To understand and thereby control the manufacturing process of goat cheese, it is essential to find an objective and quantitative method that will reveal how the particles are joined together and how the whey is retained in the protein matrix. The aim of this work was to develop and apply a procedure using scanning electron microscopy and image analysis to quantify differences in the microstructure (pore number, area and perimeter, strand thickness, and porosity) at different times of an industrial goat cheese manufacturing process.

\section{MATERIALS AND METHODS}

\section{Samples}

Curd samples were obtained during the industrial manufacture of "Queso de Murcia al Vino," a cheese made with pasteurized Murciano-Granadina goat milk. The cheeses were produced by an industrial company, following the rules for the production of Protected Denomination of Origin Queso de Murcia al Vino. Cheesemaking was carried out in a 10,000-L vat. When milk reached $33.3^{\circ} \mathrm{C}$, rennet (chymosin $85 \%$ ) was added at a concentration of $0.026 \mathrm{mg} / \mathrm{L}$.

The samples were taken on 8 production days to study the microstructure parameters by applying the procedure described below. Samples were taken using sterile $250-\mathrm{mL}$ plastic containers at different times of the goat cheese production process: $34 \pm 1 \mathrm{~min}$ (cutting), $154 \pm 6$ min (before molding), and $293 \pm 35$ min (after pressing) after the start of the coagulation process. The samples were fixed as described below, transported at $4^{\circ} \mathrm{C}$, and processed immediately upon reception. Four replicates were processed for each sample, and 2 scanning electron microscopy images were analyzed per replicate. A total of 48 values were considered for the study.

\section{Scanning Electron Microscopy}

Samples were immediately fixed at the factory in 0.2 $M$ sodium cacodylate containing glutaraldehyde and formaldehyde for $48 \mathrm{~h}$ at $4^{\circ} \mathrm{C}$, as described by McDowell and Trump (1976). Upon reception in the laboratory, 4 slices (2 to $6 \mathrm{~mm}$ thick) were cut vertically for each curd sample. The samples were then rinsed for $24 \mathrm{~h}$ at $4^{\circ} \mathrm{C}$ with $0.2 M$ cacodylate and saccharose buffer before and after being fixed with $\mathrm{OsO}_{4}$ at $1 \%$. The fixed samples were dehydrated in a graded acetone series of 30,40 , 50,90 , and $100 \%$ in steps of 40 min before critical point drying (Balzers Union CPD-020, Vaduz, Liechtenstein). Samples were glued on the sample holder, coated with gold (Bio-Rad Polaron Division 200A, Watford, UK), and observed at $15 \mathrm{kV}$ (Jeol T-300 SEM, Sollentuna, Sweden). The internal surface of the samples was observed at $6,500 \times$ magnification. Two representative areas of each piece of the sample were randomly selected and scanned in a horizontal direction at a distance of $9 \mathrm{~mm}$. At least 6 micrographs were captured for each sample (Inca Oxford image capture system, Oxford Instruments Analytical Ltd., High Wycombe, UK). This procedure is based on the method described by Boutrou et al. (2002), with modifications.

\section{Image Analysis}

To compute the microstructure parameters, micrographs were analyzed by means of the image analysis software MIP v4.5 (Consulting Image Digital, Barcelona, Spain) in a blind manner. Porosity was defined as the division of the pore area by the total image area (Impoco et al., 2006). Pore is a structural unit defined as the free cavity between many protein links on the microstructure surface (Buffa et al., 2001).

Different parameters related to pore microstructure were also analyzed: pore number, as observed in the image surface; pore area, as the total square micrometers of each pore surface considering all the irregularities; and pore perimeter, defined as the whole of the pore edge or boundary, measured in micrometers and also considering its irregularities. Strands were defined as 
the union between aggregates in the protein matrix (Boutrou et al., 2002). For such structural strands, thickness was taken as a microstructure parameter and defined as the distance from one side of the strand to the other, perpendicular to the strand direction vector.

Micrographs were transformed into 8-bit binary images of $1,024 \times 786$ pixels and then normalized in the same conditions to guarantee the correct and standard contrast for all the images. Before quantification, all the micrographs were calibrated according to the magnification of the image.

For the variables porosity, pore number, pore area, and pore perimeter, the gray levels were segmented to identify which pixels belonged to pores and which to the protein matrix regions. Gray segmentation was made in the same conditions for all the images, and the pixels below a gray value of 47 were selected. Porosity in the binary image was calculated as the percentage of white area (free space in the protein matrix) with respect to the total image area (Impoco et al., 2006). Interactive measurements were used for calculation of the strand thickness. A perpendicular line of the strand direction vector was drawn in an interactive way from one side of the strand to the other, and measured as the total distance in micrometers was measured.

\section{Statistical Analysis}

Statistical treatment of the data was performed using SPSS version 15.0 (2006, SPSS Ibérica S.L.U., Madrid, Spain). Descriptive analyses, one-way ANOVA, the Kolmogorov-Smirnov normality test, and a Pearson correlation test were used with a significance level of $P<0.05$.

\section{RESULTS AND DISCUSSION}

To provide a visual characterization, the representative scanning electron microscopy images, the corresponding gray level, and binary images are illustrated in Figure 1. From the images, differences in the protein matrix (Figure 1A, B, and C) can be observed between the 3 production times selected, each of which has characteristic structural features that reflect the effect of the different cheesemaking steps involved in the manufacture: the cutting, stirring, heating, and washing steps between times $\mathrm{A}$ and $\mathrm{B}$, and the pressing step between times B and C.

As can be observed, the gray level (Figure 1A', B', and $\mathrm{C}^{\prime}$ ) makes it possible to detect each of the pores and the irregularities present in the microstructure, whereas the corresponding binary images (Figure 1A",
$\mathrm{B}^{\prime \prime}$, and $\mathrm{C}^{\prime \prime}$ ) allow quantification of porosity and the number of pores.

As was described by Boutrou et al. (2002), the microstructure development of cheese begins with the rearrangement of casein micelles to form the micelle aggregates of the protein matrix. This state corresponds to the images obtained at time A where a more disaggregated structure with a higher number of pores is visualized (Figure 1A, B, and C). As can be observed in Figure $1 \mathrm{~A}^{\prime}$, the aggregates are irregularly shaped, which gives rise to a high number of free cavities throughout the protein matrix, in contrast with the curd microstructure from times $\mathrm{B}$ and $\mathrm{C}$ (Figure $1 \mathrm{~B}^{\prime}$ and $\mathrm{C}^{\prime}$ ), where the aggregates touch to form a continuous network in the same way as was described for rennet curd syneresis by Dejmek and Walstra (2004). Moreover, the binary images $\left(\mathrm{A}^{\prime \prime}, \mathrm{B}^{\prime \prime}\right.$, and $\left.\mathrm{C}^{\prime \prime}\right)$ show differences in the total free area (white area) of the protein matrix (black area), which is related to curd porosity, which is defined as the ratio between black and white areas. The same visual evidence was provided by the confocal scanning laser microscopy images obtained by López et al. (2007) in a study of the development of milk fat microstructure during the manufacture and ripening of Emmental cheese.

Table 1 depicts the following statistical values obtained for each of the manufacturing times selected: mean, Fisher's coefficient of skewness $\left(\mathrm{g}_{1}\right)$ and coefficient of variation $(\mathrm{CV})$, the values of which indicate the acceptability of the results obtained with this procedure. These statistical determinations were made for 48 images, giving a total of 48 values for porosity and pore number ( 1 for each image). A total of 288 values for strand thickness (6 strands per image selected according to the description defined above), and 11,126, 8,736 , and 8,671 values for pore area and perimeter at times A, B, and C, respectively (according to the value of the area and perimeter of each pore identified and computed for each of the 48 images).

A greater number of pores and greater pore perimeter and area were measured at time A compared with times B and C, as shown in Table 1. This confirms the visual evidence described previously for Figure 1. The microstructure observed at the second time is clearly different from that observed at the first time.

These results are in contrast with those of Boutrou et al. (2002) who, by simply measuring the porous diameter, concluded that during drainage the open spaces that contain the aqueous phase are always uniformly dispersed and of the same size. In this study, the process of drainage corresponded to the period between $\mathrm{A}$ and B. At this second time $(154 \pm 6 \mathrm{~min})$, clear decreases in porosity, pore number, area and perimeter 


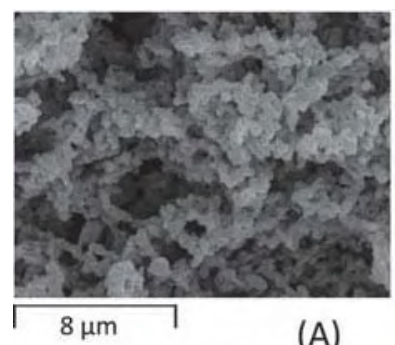

(A)

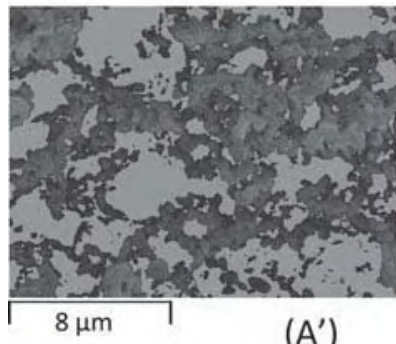

$\left(A^{\prime}\right)$

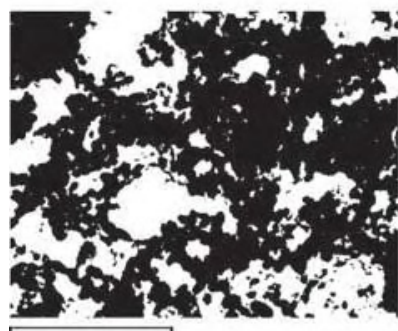

$\left(A^{\prime \prime}\right)$

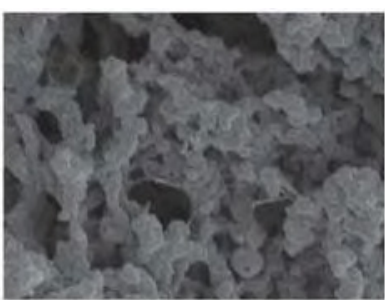

(B)

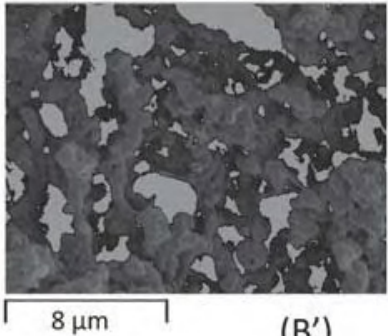

(B')

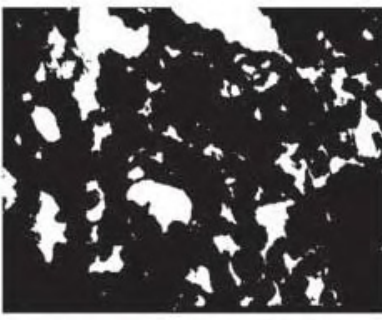

(B")

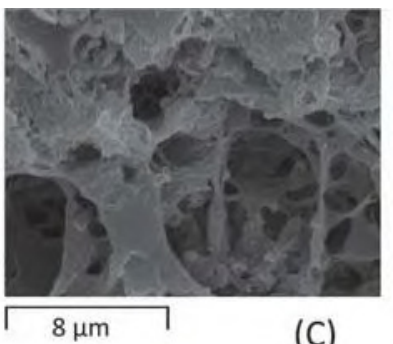

(C)

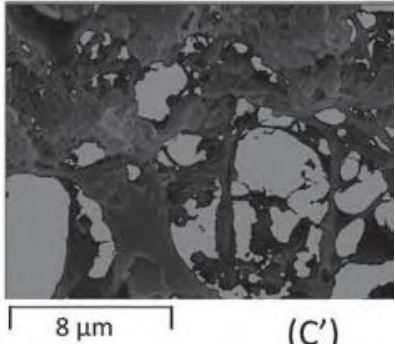

(C')

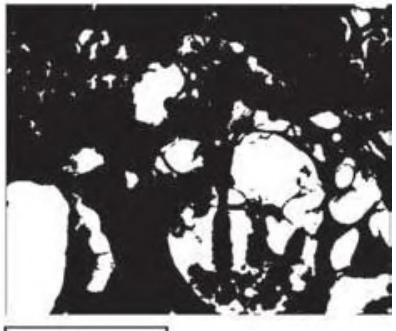

$\left(C^{\prime \prime}\right)$

Figure 1. Scanning electron microscopy images of goat curd at $6,500 \times$ magnification and corresponding binary images: industrial goat curd at (A) $34 \pm 1 \mathrm{~min}$; (B) $154 \pm 6 \mathrm{~min}$; and (C) $297 \pm 35 \mathrm{~min} ; \mathrm{A}^{\prime}, \mathrm{B}^{\prime}$, and $\mathrm{C}^{\prime}$ are the corresponding gray level detection images; $\mathrm{A}^{\prime \prime}, \mathrm{B}^{\prime \prime}$, and $\mathrm{C}^{\prime \prime}$ are the corresponding binary images.

were observed, whereas the strands were thicker. These decreases could be related to the processes of cutting and stirring, as both are thought to increase the collision between curd particles, promoting consolidation of the protein matrix (Birkkjaer et al., 1961; Patel et al., 1972).

Dejmek and Walstra (2004) attributed the enhancement of compaction to the pressing process. Pressing takes place between $154 \pm 6 \mathrm{~min}$ and $293 \pm 35 \mathrm{~min}$, so this effect could explain the increase in strand thickness between times $\mathrm{B}$ and $\mathrm{C}$.

The samples at $34 \pm 1$ min showed higher standard deviation values and greater dispersion than the samples at times $154 \pm 6 \mathrm{~min}$ and $293 \pm 35 \mathrm{~min}$ for all parameters measured except strand thickness, for which the standard deviation was lower, and pore area and perimeter, for which the CV was higher. As previously discussed for Figure 1, a disaggregated structure was evident at time A, which meant that the samples were more heterogeneous, allowing a less reproducible and repetitive analysis. This explains why the standard deviation values for porosity, pore number, area, and perimeter and the $\mathrm{CV}$ value for pore area are higher at time $\mathrm{A}$, whereas at time $\mathrm{C}$, with a more continuous protein matrix, they are lower.

A mean value is considered representative when the CV is $<30 \%$. Mulla and Mc Bratney (2002) considered a $\mathrm{CV}$ as moderate to low when $<21 \%$ and high when $>41 \%$. As can be seen in Table 1 , most of the results obtained show moderate dispersion for all group samples and all parameters analyzed, except for pore number at time $\mathrm{C}$, pore area at time $\mathrm{A}$, and porosity at time $\mathrm{B}$, all of which presented moderate to high values, and pore area at time $\mathrm{B}$, which presented a high CV not considered representative. An acceptable $(<2)$ Fisher coefficient of skewness was also obtained 
Table 1. Characterization of microstructure parameters

\begin{tabular}{|c|c|c|c|}
\hline \multirow[b]{2}{*}{ Parameter } & \multicolumn{3}{|c|}{ Sampling time ${ }^{1}$} \\
\hline & A & B & $\mathrm{C}$ \\
\hline \multicolumn{4}{|l|}{ Pore number } \\
\hline $\mathrm{n}$ & 48 & 48 & 48 \\
\hline Mean \pm SD & $246.33 \pm 62.44$ & $177.54 \pm 46.61$ & $180.64 \pm 61.62$ \\
\hline $\mathrm{g}_{1}^{2}$ & 1.33 & -0.23 & 1.33 \\
\hline $\mathrm{CV}$ & 21.72 & 25.80 & 30.04 \\
\hline$P$-value (ANOVA) & 0.816 & 0.880 & 0.018 \\
\hline \multicolumn{4}{|l|}{ Pore area $\left(\mu \mathrm{m}^{2}\right)$} \\
\hline $\mathrm{n}$ & 11,126 & 8,736 & 8,671 \\
\hline Mean \pm SD & $0.33 \pm 0.12$ & $0.22 \pm 0.09$ & $0.24 \pm 0.08$ \\
\hline $\mathrm{g}_{1}$ & 0.19 & 1.62 & 0.67 \\
\hline $\mathrm{CV}$ & 36.41 & 41.82 & 24.01 \\
\hline$P$-value (ANOVA) & 0.124 & 0.790 & 0.001 \\
\hline \multicolumn{4}{|l|}{ Pore perimeter $(\mu \mathrm{m})$} \\
\hline $\mathrm{n}$ & 11,126 & 8,736 & 8,671 \\
\hline Mean $\pm \mathrm{SD}$ & $1.88 \pm 0.50$ & $1.60 \pm 0.33$ & $1.61 \pm 0.37$ \\
\hline $\mathrm{g}_{1}$ & -0.61 & 1.01 & 0.33 \\
\hline $\mathrm{CV}$ & 26.59 & 20.72 & 16.18 \\
\hline$P$-value (ANOVA) & 0.323 & 0.973 & 0.001 \\
\hline \multicolumn{4}{|l|}{ Strand thickness $(\mu \mathrm{m})$} \\
\hline $\mathrm{n}$ & 288 & 288 & 288 \\
\hline Mean $\pm \mathrm{SD}$ & $0.24 \pm 0.04$ & $0.45 \pm 0.11$ & $0.67 \pm 0.17$ \\
\hline $\mathrm{g}_{1}$ & -0.61 & 0.49 & 0.48 \\
\hline $\mathrm{CV}$ & 18.11 & 25.89 & 22.38 \\
\hline$P$-value (ANOVA) & 0.160 & 0.275 & 0.022 \\
\hline \multicolumn{4}{|l|}{ Porosity (\%) } \\
\hline $\mathrm{n}$ & 48 & 48 & 48 \\
\hline Mean \pm SD & $36.82 \pm 5.83$ & $11.50 \pm 4.20$ & $14.42 \pm 3.98$ \\
\hline$g_{1}$ & -0.10 & 0.20 & -0.04 \\
\hline $\mathrm{CV}$ & 13.65 & 38.09 & 22.38 \\
\hline$P$-value (ANOVA) & 0.931 & 0.990 & 0.009 \\
\hline
\end{tabular}

${ }^{1} \mathrm{~A}=$ samples at $34 \pm 1 \mathrm{~min} ; \mathrm{B}=$ samples at $154 \pm 6 \mathrm{~min} ; \mathrm{C}=$ samples at $293 \pm 35 \mathrm{~min}$.

${ }^{2} \mathrm{~g}_{1}=$ Fisher's coefficient of skewness.

for all parameters. These results show that microstructure changes during the cheese making process and that these changes can be quantified with good results.

The values shown in Table 1 can be considered indicators of curd microstructure during the manufacture of goat cheese, because no references are found for the quantification of such parameters. The only values that can be compared with those of our study are the results obtained by Impoco et al. (2006) for porosity (0.17 to 0.39) corresponding to different Sicilian cheeses at different ripening ages. The values obtained for this study at the latest time (C samples) were from recently pressed, unripened cheeses.

Table 2 shows the results of the one-way ANOVA and a post hoc Tukey test to identify significant statistical differences $(P<0.05)$ between group samples. Significant statistical differences were found when samples at $34 \pm 1$ min were compared with those at $154 \pm 6$ min and $293 \pm 35$ min for all parameters, whereas no significant differences were found between samples in the latter 2 times $(154 \pm 6 \mathrm{~min}$ and $293 \pm 35 \mathrm{~min})$ except for strand thickness. From these results, we can confirm that during cheesemaking the microstructure undergoes significant development from the beginning of coagulation to molding of the curd. It seems that the mechanical shear involved in the cutting and stirring processes of cheese manufacture imparts different features to the curd microstructure, as discussed by Dejmek and Walstra (2004).

Moreover, the results shown in Table 2 agree with those in Table 1. The passage of time leads to a more compact network, as observed by scanning electron microscopy during cheese manufacture (Boutrou et al., 2002) and by transmission electron microscopy for cheeses during storage (Tunick et al., 1997). The procedure described in this study clearly characterized the parameters involved in microstructure and their variation during the manufacturing process, with representative results.

However, Table 2 points to no statistical differences between B and C (no significant changes in porosity, pore number, area, or perimeter of the curd from molding to the pressing process), although such differences were evident from Figure 1. This reveals the limitations involved in the visual perception of 3-dimensional images, which highlights the need for a procedure able 
Table 2. Effect of the production time (samples A, B, C) on the microstructural parameters (post hoc test of Tukey)

\begin{tabular}{|c|c|c|c|c|c|}
\hline Item $^{1}$ & $\begin{array}{c}\text { Pore } \\
\text { number }\end{array}$ & $\begin{array}{l}\text { Pore area } \\
\left(\mu \mathrm{m}^{2}\right)\end{array}$ & $\begin{array}{c}\text { Pore } \\
\text { perimeter }(\mu \mathrm{m})\end{array}$ & $\begin{array}{c}\text { Strand } \\
\text { thickness }(\mu \mathrm{m})\end{array}$ & $\begin{array}{l}\text { Porosity } \\
(\%)\end{array}$ \\
\hline $\mathrm{A}$ & 231.79 & 0.39 & 2.05 & 0.26 & 37.59 \\
\hline B & 182.00 & 0.23 & 1.63 & 0.49 & 12.40 \\
\hline $\mathrm{C}$ & 180.64 & 0.24 & 1.61 & 0.67 & 14.42 \\
\hline df & 143 & 143 & 143 & 143 & 143 \\
\hline$F$-value & 10.41 & 27.88 & 13.84 & 129.16 & 437.68 \\
\hline$P$-value & $* * *$ & $* * *$ & $* * *$ & $* * *$ & $* * *$ \\
\hline$A$ vs. $B$ & $49.79^{* * *}$ & $0.16^{* * *}$ & $0.41^{* * *}$ & $-0.23^{* * *}$ & $25.19^{* * *}$ \\
\hline A vs. C & $51.14^{* * *}$ & $0.15^{* * *}$ & $0.43^{* * *}$ & $-0.41^{* * *}$ & $23.19^{* * *}$ \\
\hline B vs. C & $1.35^{\mathrm{NS}}$ & $-0.00^{\mathrm{NS}}$ & $0.01^{\mathrm{NS}}$ & $-0.17^{* * *}$ & $-2.02^{\mathrm{NS}}$ \\
\hline
\end{tabular}

to quantify curd microstructure parameters and their changes. Moreover, it can be concluded that during the manufacture of this type of cheese, the molding and pressing processes did not significantly affect the area, number, or perimeter of pores but did influence strand thickness.

If strand thickness is related to curd compaction, the fact that strand thickness significantly changed during the molding and pressing processes reflects the observations of Dejmek and Walstra (2004), who stated that the pressing process enhances curd compaction.

Table 3 shows the results of the Pearson correlation test carried out to ascertain whether any relation between the parameters measured might provide information about which parameters can be used to predict other parameters. A negative interaction was observed between pore number, pore area, pore perimeter, and strand thickness, at a significance level of $P<0.001$. Strand thickness and pore area and perimeter decreased as pores number increased. Pore area was related not only to perimeter and strand thickness, as was expected, but also to microstructure porosity. Higher area values were related to higher perimeter and porosity values and lower strand thickness values. As regards porosity, the results point to a positive interaction with pore number, area, and perimeter, and a negative interaction with strand thickness. All the parameters analyzed are intercorrelated and demonstrate a high degree of correlation with porosity, which plays an important role in texture perception (Langton et al., 1996), so it can be assumed that the variables defined and the method described in this work can be regarded as good tools for future study of the relation between microstructure and the final product texture.

The high correlation coefficients between all the studied parameters, especially those related to porosity, confirm the capacity of scanning electron microscopy and image analysis to predict final cheese characteristics if equations relating curd microstructure and curd physicochemical parameters are developed.

\section{CONCLUSIONS}

Until now, no scientific evidence has permitted a repetitive and reproducible quantification of the microstructural parameters of curd samples by scanning electron microscopy and image analysis. Obtaining representative data with low variation is difficult due to sample heterogeneity and the correlation between the different parameters involved in the coagulation process of goat milk. The quantitative data obtained by the procedure described in this study showed normal distribution with appropriate skewness and representative means; therefore, the procedure can be considered appropriate for quantifying pore number, pore area, pore perimeter, porosity, and strand thickness, which makes

Table 3. Pearson correlation test of the microstructural parameters

\begin{tabular}{lccccc}
\hline Variable & $\begin{array}{c}\text { Pore } \\
\text { number }\end{array}$ & $\begin{array}{c}\text { Pore } \\
\text { area }\end{array}$ & $\begin{array}{c}\text { Pore } \\
\text { perimeter }\end{array}$ & $\begin{array}{c}\text { Strand } \\
\text { thickness }\end{array}$ & Porosity \\
\hline Pore area $\left(\mu \mathrm{m}^{2}\right)$ & $-0.369^{* * *}$ & & & & \\
Pore perimeter $(\mu \mathrm{m})$ & $-0.435^{* * *}$ & $0.899^{* * *}$ & & & \\
Strand thickness $(\mu \mathrm{m})$ & $-0.424^{* * *}$ & $-0.222^{* *}$ & -0.126 & & \\
Porosity $(\%)$ & $0.265^{*}$ & $0.599^{* * *}$ & $0.478^{* * *}$ & $-0.617^{* * *}$ & \\
Volume $\left(\mathrm{mm}^{3}\right)$ & 0.015 & $-0.340^{* * *}$ & $-0.318^{* * *}$ & 0.158 & $-0.339^{* * *}$ \\
\hline
\end{tabular}

${ }^{*} P<0.05 ;{ }^{* *} P<0.01 ;{ }^{* * *} P<0.001$. 
it possible to characterize curd microstructure. This procedure also makes it possible to detect and quantify any changes that take place between given stages of the process. We also conclude that the mechanical processes of curd setting (cutting, heating, stirring, and washing) influence alterations in curd microstructure. However, it would be necessary to study microstructure parameters at more stages of the cheesemaking process to determine which setting process exerts the highest influence.

\section{ACKNOWLEDGMENTS}

This work was financially supported by Fundación Séneca project 05721/PI/07. The Spanish Ministry of Education, with a research fellowship, The Central Quesera Montesinos S.L. (Murcia. Spain) and the Services of Microscopy and Image Analysis of the University of Murcia are also acknowledged.

\section{REFERENCES}

Birkkjaer, H. E., B. J. Sörensen, J. Jorgensen, and B. Sigersted. 1961. The effect of cheesemaking techniques on cheese quality. Beretn. Stat. Forsogs. 128.

Boutrou, R., M. H. Famelart, F. Gaucheron, Y. Le Graet, J. Y. Gassi, M. Piot, and J. Leonil. 2002. Structure development in a soft cheese curd model during manufacture in relation to its biochemical characteristics. J. Dairy Res. 69:605-618.

Buffa, M. N., A. J. Trujillo, M. Pavia, and B. Guamis. 2001. Changes in textural, microstructural, and color characteristics during ripening of cheeses from raw, pasteurized or high pressure treated goats' milk. Int. Dairy J. 11:927-934.

Dávila, E., and D. Parés. 2007. Structure of heat-induced plasma protein gels studied by fractal and lacunarity analysis. Food Hydrocoll. 21:147-153.
Dejmek, P., and P. Walstra. 2004. Cheese: Chemistry, Physics and Microbiology. Vol. 1. 3rd ed. P. F. Fox, ed. Chapman and Hall, London, UK.

Ding, K., and S. Gunasekaran. 1998. Three-dimensional image reconstruction procedure for food microstructure evaluation. Artif. Intell. Rev. 12:245-262.

Everett, D. W., and M. A. E. Auty. 2008. Cheese structure and current methods of analysis. Int. Dairy J. 18:759-773

Impoco, G., S. Carrato, M. Caccamo, L. Tuminello, and G. Licitra 2006. Quantitative analysis of cheese microstructure using SEM imagery. Communications to SIMAI Congress, Vol. 2: 1-10. Baia Samuele (Ragusa), Sicily, Italy.

Langton, M., A. Aström, and A.-M. Hermansson. 1996. Texture as a reflection of microstructure. Food Qual. Prefer. 7:185-191.

López, C., B. Camier, and J.-Y. Gassi. 2007. Development of the milk fat microstructure during the manufacture and ripening of Emmental cheese observed by confocal laser scanning microscopy. Int. Dairy J. 17:235-247.

McDowell, E. M., and B. F. Trump. 1976. Histologic fixatives suitable for diagnostic light and electron microscopy. Arch. Pathol. Lab. Med. 100:405-414.

Mulla, D. J., and A. B. Mc Bratney. 2002. Soil spatial variability. Precis. Agric. 3:343-373.

Patel, M. C., D. B. Lund, and N. F. Olson. 1972. Factors affecting syneresis of renneted milk gels. J. Dairy Sci. 55:913-918.

Pinho, O., E. Mendes, M. M. Alves, and I. M. Ferreira. 2004. Chemical, physical, and sensorial characteristics of "Terrincho" ewe cheese: Changes during ripening and intravarietal comparison. J. Dairy Sci. 87:249-257.

Stanley, D. W. 1987. Food texture and microstructure. Pages 35-64 in Food Texture. H. R. Moskowitz, ed. Marcel Dekker Inc., New York, NY.

Thorvaldsson, K., M. Stading, K. Nilsson, S. Kidman, and M. Langton. 1999. Rheology and structure of heat-treated pasta dough: Influence of water content and heating rate. Lebenson. Wiss. Technol. 32:154-161.

Tunick, M. H., P. H. Cooke, E. L. Malin, P. W. Smith, and V. H. Holsinger. 1997. Reorganization of casein submicelles in Mozzarella cheese during storage. Int. Dairy J. 7:149-155.

Wium, H., P. S. Pedersen, and K. B. Qvist. 2003. Effect of coagulation conditions on the microstructure and the large deformation properties of fat-free Feta cheese made from ultrafiltered milk. Food Hydrocoll. 17:287-296. 